\title{
Correction to: Reflections on designing population surveys for COVID-19 infection and prevalence
}

\author{
Akshay Swaminathan • S. V. Subramanian
}

Published online: 8 September 2020

(C) American Aging Association 2020

\section{Correction to: GeroScience \\ https://doi.org/10.1007/s11357-020-00253-6}

The article Reflections on designing population surveys for COVID-19 infection and prevalence, written by Akshay Swaminathan and S. V. Subramanian, was originally published electronically on the publisher's internet portal (currently SpringerLink) on 18 August 2020 with open access. With the author(s)' decision to step back from Open Choice, the copyright of the article changed on September 2020 to (C) American Aging
Association 2020 and the article is forthwith distributed under the terms of copyright.

The original article has been corrected.

Publisher's note Springer Nature remains neutral with regard to jurisdictional claims in published maps and institutional affiliations.

The online version of the original article can be found at https://doi.org/10.1007/s11357-020-00253-6

A. Swaminathan Quantitative Sciences, Flatiron Health, New York, NY 10012, USA

e-mail: akshay325@gmail.com

S. V. Subramanian $(\bowtie)$

Harvard Center for Population and Development Studies, 9 Bow Street, Cambridge, MA 02138, USA

e-mail: svsubram@hsph.harvard.edu

S. V. Subramanian

Department of Social and Behavioral Sciences, Harvard T.H.

Chan School of Public Health, Boston, MA 02115, USA 